\title{
Emphasizing the Impact of Service-Learning and Community Engagement Partnerships Amid Challenges Facing Higher Education
}

\section{Jessica Mann}

International Journal of Research on Service-Learning and Community Engagement

\section{Glenn A. Bowen}

International Journal of Research on Service-Learning and Community Engagement

\section{Recommended Citation}

Mann, J., \& Bowen, G. A. (2021). Emphasizing the impact of service-learning and community engagement partnerships amid challenges facing higher education [Introduction to IJRSLCE, 9(1)]. International Journal of Research on Service-Learning and Community Engagement, 9(1), Article 1. 
International Journal of Research on Service-Learning and Community Engagement

Volume 9, Issue 1, Article 1 | 2021 | ISSN: 2374-9466 | https://ijrslce.scholasticahq.com/

\title{
Emphasizing the Impact of Service-Learning and Community Engagement Partnerships Amid Challenges Facing Higher Education
}

\author{
Jessica Mann \\ Glenn A. Bowen \\ International Journal of Research on Service-Learning and Community Engagement
}

\begin{abstract}
Articles in Volume 9, Issue 1 of the International Journal of Research on ServiceLearning and Community Engagement (IJRSLCE) respond to the need to unpack community engagement experiences to better understand their impact on campus and in the community. Moreover, articles demonstrate research that emphasizes the impact of community-campus partnerships amid challenges currently facing higher education. In this regard, their authors share research findings that confirm transformative experiences and outcomes for community and campus stakeholders alike. Through the work of community-engaged researchers and practitioners, higher education institutions are proving their value. The research findings analyzed, lessons shared, and suggestions made demonstrate excellent work that exemplifies the transformative effects of community engagement.
\end{abstract}

Keywords: evaluation, impact, partnerships, service-learning, transformative engagement

Institutions of higher education have grappled with their civic mission for roughly 30 years. Although our understanding of service-learning and community engagement (SLCE) and their associated best practices has evolved over the years, the "engagement movement," as described by Hartley and Saltmarsh (2016), has always been focused on "assert[ing] the core democratic purpose of higher education and [at directing] its core activities toward addressing the pressing issues that face society locally, nationally, and globally" (pp. 35-36). Given the widespread institutional interest in community engagement, it is fair to say that numerous institutions have come to grips with the prioritization of their civic mission.

Over the years, scholar-practitioners in the SLCE field have developed programs, pedagogies, and research projects with a community focus. Indeed, many institutions have been "achieving the promise of public scholarship" (Alter, 2005, p. 461). In the process, they have connected the qualities and values of engagement directly to the community through reciprocal partnerships, anchoring institutions to the community at various levels - from local to global.

The sustained interest in community engagement and its added value has correlated with the shift of institutional positioning as universities branded themselves as places of learning, rather than of teaching, thus promoting their ability to cultivate environments where students - alongside their peers, faculty, and community members - co-construct knowledge, address issues, and solve problems. SLCE practitioners understand that this branding strategy calls for community-focused 
experiences so that participants can "access multiple knowledge commons" and engage collaboratively with others (Longo \& Gibson, 2016, p. 64). In this regard, SLCE work explicitly highlights how universities can participate in community life as institutional citizens, which is crucial if the field is to maintain its relevance and credibility during these times of collective stress. The current anxiety stems from the prevailing pandemic (COVID-19), which has increased the financial pressure on colleges and universities. Many institutions had already been contending with enrollment declines, attributed largely to the high cost for students, exacerbated by negative arguments about the economic value and overall benefits of a college education (Bowen, 2021; see also Busteed, 2019).

The kind of work undertaken by SLCE scholar-practitioners, as reflected in the content of Volume 9, Issue 1, of the International Journal of Research on Service-Learning and Community Engagement (IJRSLCE), is critical, because it responds to the need to unpack community engagement experiences to better understand their impact on campus and in the community. Articles in this issue demonstrate research that emphasizes the impact of SLCE partnerships amid the challenges facing higher education. Authors acknowledge the need for evaluation of community engagement initiatives and community-campus partnerships to test and gauge their instrumentality as agents of transformation benefiting stakeholders (Calderón, 2017; Nelson \& Stroink, 2020). Furthermore, the authors share community-engaged research findings that confirm transformative experiences and outcomes for community and campus stakeholders alike.

As summarized below, articles in this issue have been placed in four major categories (i.e., IJRSLCE sections): Advances in Theory and Methodology; Student Outcomes (Primary, Secondary, and Higher Education); Community Partnerships and Impacts; and International Service-Learning and Community Engagement Research.

\section{Advances in Theory and Methodology}

The Advances section contains a single article, "Evaluating the Reliability of the PRELOAD Rubric: Assessment of Service-Learning Course Syllabi," by Sally L. Haack, Stacy Gnacinski, Inbal Mzar, and Anisa Hansen. Their study responded to the need for faculty support related to service-learning course design to ensure a reciprocal and contextualized experience for students, faculty, and community partners. The researchers set out to evaluate the interrater reliability of the rubric in practice as "an evidence-based method" (The Course Syllabus, para. 6) because they recognized that faculty development and appropriate syllabus construction are key elements for achieving learning outcomes as well as institutional engagement goals. The findings of this study could encourage extensive interest in the rubric and its ultimate use, despite its limitations.

\section{Student Outcomes (Primary, Secondary, and Higher Education)}

The two articles included in this section examine how thoughtfully designed service-learning courses, with intentional reflection, can assist in the personal and professional development of student participants. One looks at outcomes for aviation science students, the other at outcomes for students taking criminal justice statistics.

In "Service-Learning in a Professional Discipline," Stephen Belt and Leah Sweetman report their analysis of reflections by students in a community-engaged aviation science course. Findings touched on themes of teaching, connectedness, and potential community barriers-highlighting not only the value students ascribed to the experience but also their ability to critically examine the experience and their own roles within the community context. 
In the second Student Outcomes article, Kimberley Schanz and Kaela Giles use data from a criminal justice statistics class to determine how a service-learning pedagogical model could be incorporated effectively into more nontraditional course structures. This quasi-experimental study provides evidence that service-learning had a positive impact on both the students' understanding of statistics and its applicability to the criminal justice field. The authors indicate that the servicelearning experience also informed participants' future career plans while helping them to hone their professional skills for career success.

\section{Community Partnerships and Impacts}

In this section, the articles contain descriptions and analyses of different community-university partnerships. The articles are based on studies that examined collaboration strategies to effect positive social change while informing curricula.

Yolanda Ornelas, Jennifer Saxton, Patricia Kohler-Evans, Anita Sego, and Lesley Graybeal discuss their case study of cross-sector collaboration aimed at improving a juvenile court system in the southern United States. The researchers designed their study in response to a state legislature-identified need to implement risk assessment and related programming for courtinvolved youth. The researchers found that the collaborative model, involving government officials, nonprofit leaders, and education institutions, was essential to the successful implementation of the model, which resulted in participants' holistic understanding of the social issue and the impact of the intervention.

A community-university-extension project encompassing a satellite food pantry is the subject of the second article in this section of the Journal. Food for a Long Life used intergenerational strategies and a community-based participatory action research approach to increase healthy food access, consumption, and education for preschool children and older adults. Chapter coauthors Jill Juris, Elizabeth Speidel, Lauren Bailey, and Shannon E. Jarrot describe the initiative and explain the outcomes realized so far.

This section's final article - by Myah Pazder, Kajua B. Lor, Otis Winstead Jr., L. Kevin Hamberger, Bob Curry, Zeno Franco, Sarah O'Connor, Martina Gollin-Graves, Robert Hurley, Tiffiney Gray, and Syed M. Ahmed - is about a peer-delivered opioid prevention curriculum. The research team assessed a statewide initiative aimed at addressing opioid misuse among a Veteran population primarily through peer training. Further, their study looked at the effectiveness of the comprehensive, community-engaged effort, which was designed collaboratively by representatives of nonprofit organizations, higher education institutions, and healthcare systems. Pazder et al. report that the study produced a comprehensive understanding of the initiative's impact and a "nuanced perspective that fostered a deeper appreciation of the knowledge and service gaps" among Veterans (Conclusion, para. 1).

\section{International Service-Learning and Community Engagement Research}

The largest section of this issue focuses on the construction of knowledge bases and research agendas for international service-learning (ISL) and community engagement. The four articles examine the effects of global engagement, offering insight into best practices and beneficial outcomes.

In the first article, researchers in Hong Kong contribute to the literature by analyzing a large multicourse data sample to draw conclusions about the impact of ISL on students' development of global citizenship and intercultural effectiveness. Stephen C. F. Chan, Grace Ngai, Jessie Ho-Y in Yau, and Kam Por Kwan share findings and discuss pertinent implications. 
In the second article, Myriam Vučković, Sarina Neote, and Annie Pruitt Gravley examine the medium- and long-term effects of global engagement on American undergraduates who participated in a semester-long Practical Experience Abroad (PEA). According to the authors,

Beyond the benefits of traditional study abroad, the immersive and experiential nature of their research semester abroad helped students develop global health competencies, which cannot be taught in a traditional academic setting. Their participation in the PEA gave them an initial advantage in the competitive global health job market and helped to prepare them for a broad spectrum of global health-related professions and graduate programs. (Discussion, para. 6)

"Cultivating Cross-Cultural Learning and Collaboration Among Special Educators Engaged in International Service-Learning," by Amy Rose and her colleagues, has a focus similar to Vučković et al.'s article. Rose et al. examined the effects of ISL on special educators and speechlanguage pathology students who had an engagement experience in Botswana. The researchers found that the students expanded their perspectives, gained cultural humility, increased their professional confidence, and developed the skillsets necessary to collaborate across difference.

The last article in this section offers a perspective markedly different from that conveyed by the program-focused studies, through a systematic synthesis of the best practices of global servicelearning (GSL). Jason K. Hawes et al. map 18 guiding principles for project design. (Hawes's coauthors are Rebecca Johnson, Lindsey Payne, Christian Ley, Caitlin A. Grady, Jennifer Domenech, Carly D. Evich, Andrew Kanach, Allison Koeppen, Kirsten Roe, Audrey Caprio, Jessica Puente Castro, Paige LeMaster, and Ernest R. Blatchley.) Their collaborative effort brings attention to partnerships, course design, project implementation, and core principles, and it encourages the practical and effective use of the identified principles for the development and implementation of sustainable GSL projects.

\section{Book Reviews}

Two books are reviewed in this issue. In the first review, Stephanie Bingham offers an assessment of Service Learning to Advance Access and Success: Bridging Institutional Capacity (edited by Travis T. York, Alan S. Tinkler, \& Barri E. Tinkler). As the reviewer notes, the 12-chapter volume offers diverse and innovative ways for new and seasoned service-learning practitioners alike to implement service-learning initiatives effectively. Bingham views the partnerships described in the book as potentially "transformative, functioning as a force for positive change in higher education" (para. 13).

The second book review, by Laura Finley, critiques Food for Thought: Service-Learning Research in Asia (edited by Robert Shumer, Carol Ma Hok Ka, \& Constance Chan Wing Yee). This volume showcases an abundance of service-learning initiatives in Asia. The chapters represent a variety of disciplinary areas and civic foci. Finley calls it "a useful book for understanding how to utilize service-learning in different disciplines as well as how to institutionalize it and support educators" (para. 3).

\section{Conclusion}

Although articles in this issue of IJRSLCE do not specifically address the public skepticism about the value of a college education or about the challenges for higher education posed by COVID-19, their publication is opportune. Through the work of SLCE researchers and practitionersuniversity faculty and staff members, sometimes with students - higher education institutions are proving their value. Their value is evidenced, in some measure, by the work featured in these articles. The research findings analyzed, lessons shared, and suggestions made demonstrate excellent work and offer much hope for institutions, buttressed by their partnerships with 
community entities and by the gains made by students sharing in the transformative effects of community engagement.

\section{References}

Alter, T. R. (2005). Achieving the promise of public scholarship. In S. J. Peters, N. R. Jordan, M. Adamek, \& T. R. Alter (Eds.), Engaging campus and community: The practice of public scholarship in the state and land-grant university system (pp. 461-488). Kettering Foundation Press.

Bowen, G. A. (2021). Community-focused experiential learning: Creating conditions for fostering a sense of social responsibility. In L. L. Finley \& G. A. Bowen (Eds.), Experiential learning in higher education: Issues, ideas, and challenges for promoting peace and justice (pp. 1-20). Information Age Publishing.

Busteed, B. (2019, September 3). The convincing and confusing value of college explained. Forbes. https://www.forbes.com/sites/brandonbusteed/2019/09/03/the-convincing-andconfusing-value-of-college-explained/?sh $=5 \mathrm{ad} 721 \mathrm{f} 2372 \mathrm{~d}$

Calderón, J. Z. (2017). Transformative community engagement: Democratic trend for the future. In C. Dolgon, T. D. Mitchell, \& T. K. Eatman (Eds.), The Cambridge handbook of servicelearning and community engagement (pp. 500-510). Cambridge University Press.

Hartley, M., \& Saltmarsh, J. (2016). A brief history of a movement: Civic engagement and American higher education. In M. A. Post, E. Ward, N. V. Longo, \& J. Saltmarsh (Eds.), Publicly engaged scholarship: Next-generation engagement and the future of higher education (pp. 34-60). Stylus Publishing.

Longo, N. V., \& Gibson, C. M. (2016). Collaborative engagement: The future of teaching and learning in higher education. In M. A. Post, E. Ward, N. V. Longo, \& J. Saltmarsh (Eds.), Publicly engaged scholarship: Next-generation engagement and the future of higher education (pp. 61-75). Stylus Publishing.

Nelson, C., \& Stroink, M. (2020). Understanding the dynamics of co-creation of knowledge: A paradigm shift to a complexity science approach to evaluation of community-campus engagement. Michigan Journal of Community Service Learning, 26(1). https://doi.org/10.3998/mjcsloa.3239521.0026.112

\section{About the Authors}

Jessica Mann is assistant vice president of community engagement at Duquesne University and coeditor of the International Journal of Research on Service-Learning and Community Engagement.

Glenn A. Bowen is executive director of the Center for Community Service Initiatives at Barry University and coeditor of the International Journal of Research on Service-Learning and CommunityEngagement.

Correspondence concerning this article should be addressed to Jessica Mann at mannj@,duq.edu and Glenn A. Bowen at gbowen@barry.edu. 